\title{
A CASE STUDY OF FACTORS CONTRIBUTING TO SUCCESSFUL SECOND LANGUAGE ACQUISITION
}

\author{
Terri Chen \\ Central Michigan University, USA \\ leilq@cmich.edu
}

\begin{abstract}
Every case of second language learning is different, but they are often influenced by systematic factors. What causes a learner to succeed or fail? In this case study, the language learning experiences of a single nonnative English speaker who successfully acquired English sheds light on the interplay between several of these aspects. An interview with a single adult subject reveals that for this particular individual, a high aptitude, as well as identity and personality characteristics that aligned with an openness to experience and learning in general, were more effective than factors of motivation. While identifying how and why a single individual may be successful or unsuccessful might not be generalizable to all learners, it can serve as a tool in helping to understand differences in L2 learning success.
\end{abstract}

Keywords: SLA, aptitude, personality.

\section{Introduction}

Unlike first language acquisition, second language acquisition is less likely to be successfully acquired. Second language learners' proficiencies also vary immensely not only in level but also in type, and frequently all within one individual. It is not uncommon, for instance, for speakers to be more proficient in receptive skills than in productive ones. Furthermore, no two learners may be operating under the same circumstances. These differences can be accounted for by a plethora of factors that influence the learner's experiences and their eventual success or failure in acquiring that second language. In this study, one nonnative speaker of English is interviewed about her personal experience, and the responses examined in the context of existing second language learning research.

\section{Participants and methods}

The single adult participant interviewed was a native Taiwanese and Mandarin speaker who began learning English in her adolescence, then immigrated to the United States 11 years later, where she has resided since. While this individual's English is phonetically not native-like, its fluency indicates that the language has been successfully acquired. For the duration of this study the interviewee is referred to as Beth.

A single interview lasting one hour was conducted with the participant. A set of prepared, openended questions aimed at understanding different aspects of her individual language learning experience was 
administered in person, and the subsequent responses were recorded as typed notes. No other recording was made.

\section{Motivation}

Motivation arguably comprises one of the more complex set of factors in this case study. The reasons for this are rooted several things. Beth, the interviewee, began learning English at approximately 15 years of age, where it was mandated across the school system in Taiwan. She explicitly cites that requirement as the primary reason for beginning to learn English, but did not appear to have had any strong opinions about it one way or another. During this time her family was generally supportive of this L2 learning the way they were generally supportive of education; it was merely regarded as another school subject.

Family, peer, and general societal attitudes toward foreign or second language learning have a significant impact on the learner's interest and motivation (Donitsa-Schmidt, Inbar, \& Shohamy, 2004). Positive attitudes toward foreign culture lead to interest, interest leads to investment, and investment increases the chances of successful language acquisition. Chou (2005) studies this in Taiwan specifically, and indeed finds that positive attitudes toward English are correlated with higher self-reported proficiency, and that parental encouragement does indeed lead to higher student motivation and success. In Beth's case the parental support seemed to be present but otherwise neutral.

By the mid-1980s, the status of English in Taiwan had been firmly established as a language with relatively high linguistic capital, as one might infer from its position in public education. It was advantageous in the job market, which subsequently provided instrumental motivation for many students. Instrumental motivation certainly seems, for the most part, to be the case for Beth. It is not the sole impetus, however, because she did on some occasions enjoy using English to socialize with foreign friends and acquaintances. Nonetheless, being motivated to learn and improve upon the L2 due to necessity is an ongoing theme. Her investment in learning greatly increased upon moving to the United States, due again to necessity. Sudden immersion in a monolingual English-speaking environment obligates that English be understood, that it be used.

While integrative motivation was long considered to be the more effective of motivational types, it is not universally true (Lightbown \& Spada, 2013). In fact, Beth's attitude toward English appears largely ambivalent, both then and at the time of the interview. Being required by the curriculum to learn a new language, and being required to learn it in order to integrate oneself into a new linguistic and cultural environment can certainly prove discouraging, but she successfully acquired the target language. Evidently, other factors are at work here.

\section{Identity}

The dual fluency the interviewee holds with English and Mandarin is something very much integrated into her identity. She actively consuming and enjoying media in both languages, and regularly codeswitches in interactions with individuals who share her languages, using it when trying to explain, argue, or clarify. She reports being best able to express herself when she has access to both languages. 
Block's

poststructuralist

framework for identity explains it as something that is something that is fluid, fragmented, and constantly being negotiated and renegotiated (2007). And indeed, identity frequently if not always exists in multiplicity. Beth comfortably straddles her multilingual status, explaining that it gave one "access to two worlds." While she tends to favor Mandarin over English, she considers herself bilingual and bicultural, equally at home in either situation. Yet as a distinctly nonnative speaker, she occasionally continued to encounter others who treated her as an outsider, as nearly every nonnative speaker doubtlessly experiences.

Norton Peirce (2005) provides some additional framework for understanding how identity factors into second language learning. Cultural capital, not just linguistic capital, becomes important - a learner chooses to learn not just because the L2 is socioeconomically advantageous, but also because using that language comes with a host of cultural associations. In this particular case, both may be relevant. Like any other nonnative speaker in a new country, Beth felt the need to improve her English when she first arrived in the United States, for several reasons. There is the practical reason of communication, of course, and there is the need to negotiate one's social positioning.

\section{Personality and aptitude}

A great contributor to Beth's success in acquiring a second language lies in her personality characteristics. She is highly xenophilic, and adapts well to new social situations. More importantly, she self-identifies as enjoying learning and other novel experiences, and as being sociable and extroverted. While extroversion in itself is not necessarily an indicator of success, it does tend to correlate with lower anxiety, which does aid fluency (Lightbown \& Spada, 2013). It is important to note that fluency may come at the expense of accuracy, although they are not necessarily diametrically opposed.

Beth's L2 fluency is high. She stated that English felt comfortable and natural, and that she had little problem communicating what she means. Her willingness to communicate suffers no handicap. It is, on the other hand, difficult to gauge proficiency based on grammatical accuracy, which is in any case not covered by the scope of this study. Aptitude, however, can be analyzed in other ways. Sparks, Patton, Ganschow, and Humbach (2011) determined that aptitude is componential and does not occur uniformly. Drawing from previous studies, they also determined that "negative affective characteristics, such as low motivation... are likely to be consequences rather than causes of good and poor L2 learning" ("Discussion," para. 8). This is visibly applicable to our case.

The interviewee reports that the mode she struggled with the most while in school was writing because of the vast difference between Chinese and English writing systems, despite performing well in school in general. This difficulty perpetuated itself in the form of an aversion to writing, and to this day she still feels herself less proficient writing than in speaking, listening, or reading. Negative affect may indeed create avoidance, but that avoidance also did not exist, as is visible in this case, before the difficulty in learning was encountered.

She points out that during her time in public education, instructors 
tended to concentrate on writing and speaking - more forms of production. Very little listening at all occurred, which suggests that her high level of proficiency today is mostly naturalistically learned. The ability to continue to learn without explicit instruction, likely influenced by an innate affinity for learning, also suggests a high level of overall aptitude. Sociocultural theory and other learning conditions

The idea that language learners are more successful when they have social interaction is applicable to more than only young learners of language. The interviewee had peer support when she first began learning; because English was required in school, all her peers would also simultaneously be learning English. However, outside of the classroom little was used. She spoke it on occasion to communicate with foreigners who understood neither Mandarin nor Taiwanese, but it was not until she moved to the United States that the majority of the interaction occurred. In the beginning, she may have had to negotiate for meaning in transactional interactions, with Englishmonolingual friends and acquaintances.

Speakers who begin learning their second language after puberty, as suggested by the Critical Period Hypothesis, are not likely to attain native-like status. Beth, who began learning at the age of 15 , does not have native-like English. However, as Snow and Hoefnagel-Höhle discovered, adolescents are, under the right circumstances, able to learn at a much faster rate than children (1978). Adults performed second best. While foreign language classrooms may not have provided optimal learning conditions, it occurred during Beth's adolescence, and combined with the naturalistic learning environment present in her adulthood, it may explain how Beth was able to successfully acquire English.

\section{Conclusion}

As this analysis and discussion have demonstrated, these distinctions between the different factors that contribute to second language learning success or failure are sometimes ambiguous, and often overlap. Some aspects of L2 learning, such as the learner's own interests and capabilities, or when and where it is learned, lie outside of a typical educator's control. However, social support systems can be fostered and encouraged, for instance, or immersive learning environments can be prioritized. Merely incorporating an awareness of how identity affects how learners learn helps us to better understand why individuals might struggle or succeed where all other learning conditions appear identical.

For the most part, the learner's circumstances in this case are not so unusual they cannot be explained with the theories that have been used to evaluate them. While some of factors may tend to lead to successful L2 learning and others to unsuccessful learning, the overall outcome is successful language acquisition. Several limitations should be taken into account. First, this is a case study, and is not generalizable. Additionally, the interview conducted for this study did not ask for detailed information about classroom methods because classroom education comprised only a minor part of the interviewee's L2 learning experience, and not enough detail was provided for the study to analyze in any great depth. 


\section{References}

Block, D. (2007). The rise of identity in SLA research, post Firth and Wagner (1997). Modern Language Journal, 91, 863-76.

Chou, A. (2005). Factors affecting the learning of english: A study of the attitudes toward and motivations for learning english as a foreign language among university students in taiwan. Dissertation Abstracts International, A: The Humanities and Social Sciences, 2137-A.

Donitsa-Schmidt, S., Inbar, O. and Shohamy, E. (2004). The effects of teaching spoken Arabic on students' attitude and motivation in Israel. Modern Language Journal, 88, 217-228.
Lightbown, P. M., and Spada, N. (2013). How languages are learned ( $4^{\text {th }}$ ed.).Oxford: Oxford University Press.

Norton Peirce, B. (1995). Social identity, investment, and language learning. TESOL Quaterly, 29(1), 9-31.

Snow, C., and Hoefnagel-Höhle, M. (1978). The critical period for language acquisition: evidence from second language learning. Child Development, 49(4), 11141128.

Sparks, R. L., Patton, J., Ganschow, L., and Humbach, N. (2011). Subcomponents of secondlanguage aptitude and secondlanguage proficiency. Modern Language Journal, 95, 253-273. 
